\title{
Grand Multiparity: Obstetric Outcome in Comparison with Multiparous Women in a Developing Country
}

\author{
Charles Obinna Njoku, Sylvester Etenikang Abeshi, Cajethan Ife Emechebe \\ Department of Obstetrics and Gynaecology, University of Calabar Teaching Hospital (UCTH), Calabar, Nigeria \\ Email: charlesnjokuobinna@gmail.com
}

How to cite this paper: Njoku, C.O., Abeshi, S.E. and Emechebe, C.I. (2017) Grand Multiparity: Obstetric Outcome in Comparison with Multiparous Women in a Developing Country. Open Journal of $\mathrm{Ob}$ stetrics and Gynecology, 7, 707-718. https://doi.org/10.4236/ojog.2017.77071

Received: June 1, 2017

Accepted: July 10, 2017

Published: July 13, 2017

Copyright $\odot 2017$ by authors and Scientific Research Publishing Inc. This work is licensed under the Creative Commons Attribution International License (CC BY 4.0).

http://creativecommons.org/licenses/by/4.0/

\begin{abstract}
Grand-multiparity is a serious risk factor in pregnancy and common in developing countries. The objective was to compare the obstetric outcome of grand-multiparous women with that of low parity in our center. The study comprised of 150 grand-multiparous women (cases) and 150 multiparous women (para 2 - 4) in this index pregnancy as controls matched for age and admitted for delivery. The mean age of the grand-multiparous women at delivery was $37.0 \pm 2.8$ years. Grand-multiparity was significantly higher among women with only primary education (48.0\% versus $44.7 \%)$, polygamous marriages (9.3\% versus 3.3\%) and Muslims (17.3\% versus 6.7\%). Pregnancy induced hypertension and primary postpartum hemorrhage were significantly more often seen among grand-multiparous women than among the controls. The mean packed cell volume before delivery in the grand-multiparous women was significantly lower $(33.6 \% \pm 2.7 \%)$ than in the multiparous group $(35.2 \% \pm 2.7 \%)(\mathrm{P}$-value $=0.000)$. Grand-multiparity with its associated complications still occurs frequently in our environment. However, with adequate antenatal surveillance, optimal care during labour and contraceptive use, these problems will be reduced.
\end{abstract}

\section{Keywords}

Grand Multiparty, Postpartum Hemorrhage, Pregnancy Induced

Hypertension, Perinatal Mortality, Nigeria

\section{Introduction}

The International Federation of Gynaecology and Obstetrics (FIGO) defined grand multipara as women who have delivered fifth to ninth fetuses, whereas women who have delivered ten or more times considered to be great-grandmul- 
tiparas [1]. Shaista et al. considered grand multipara to be women who gave birth in five or more previous pregnancies after the $28^{\text {th }}$ week of gestation [2]. Grand multipara in relation to obstetric performance is labelled high risk. High risk pregnancy is defined as one in which the mother, fetus or newborn are at increased risk of morbidity or mortality before, at or after birth [2]. It has been shown that the best obstetric outcome is often seen in women who are para 1, 2 and 3 [3]. The risk to the mother and child is relatively high in first pregnancy and then this risk declines during second, third and then slowly rises with increasing parity and by the sixth pregnancy, risks exceed those of first and after that rises steeply with each pregnancy [2].

The incidence of grand multipara has decreased in most western countries since two generations due to better socioeconomic and educational status, better understanding of the limits of earth's resources and therefore higher utilisation of better more available contraception [2]. Grand multiparity is a common problem in this part of the world and when added to low socioeconomic status; it significantly increases the risk to mother and fetus and limits the resources to feed, clothe and educate the children involved and indeed the resources available to all children in a country [1]. In developed countries, grand multiparity is becoming rare, with an incidence of $1 \%-4 \%$ of all births while in developing countries like Nigeria, the incidence of grand-multiparity is between $5.1 \%$ and $18.1 \%$ [4] [5] [6].

Grand multiparous pregnancies have been considered to be at higher risk of developing antenatal complications. These complications include hypertension in pregnancy, gestational diabetes mellitus, anemia, placental abruption, placenta previa, preterm labor, mal-presentation, mal-position and feto-pelvic disproportion [7]. Other complications include uterine inertia, dysfunctional labor, uterine rupture, intrauterine death, fetal macrosomia, postpartum hemorrhage and operative deliveries with its consequent risk of maternal morbidity and mortality [7]. Socioeconomic factors play a very important part; majority of these patients are poor with inadequate access to modern perinatal care coupled with increased maternal age [1] [5]. They tend to feed their numerous children at the expense of their own nutrition, thus are prone to malnutrition [8]. They are too busy to attend to their health and due to the rapid succession of pregnancies and periods of lactation; there are subsequent iron and calcium depletion [8]. These reported complications that occur to these groups of patients during pregnancy, delivery and puerperium underscores the need for special care during antepartum, intrapartum and postpartum period [2]. Although grand multiparity has long been considered to be associated with increased maternal and fetal complications, recent studies indicated that with proper perinatal care, women with high parity rates are no longer at high risk [2]. Some authors concluded that in a developed country with optimal health care conditions, grand multiparity should not be considered dangerous [9] [10]. So the controversy concerning the risk of grand multiparity can be resolved in this environment by this study because the interventions to reduce grand multiparity and its 
complications can only be applied when the magnitude of the condition is known. Thus the aim of this study was to determine the prevalence, obstetric outcome and complications of grand multiparity in UCTH, Calabar. This will help to increase awareness, scale-up care, suggest ways to reduce these conditions, improve maternal and fetal survival and quality of life. It will also help to reduce the morbidity, mortality and economic implications associated with grand multiparity and its complications.

\section{Patients and Methods}

This prospective case control study was carried out at the Obstetrics and Gynaecology Department of the University of Calabar Teaching Hospital, Calabar, Cross River state. Cross River state has a population of 2.8 million people with Calabar as the capital city. Calabar has a population of about 371,022 people comprising a heterogenous mix of diverse cultural, religious and ethnic groups [11]. UCTH serves as a referral center for both government and private hospitals within and outside the state. The study included 150 grand multiparous women (cases) and 150 of multiparous women (para 2 - 4) as controls matched for age that were booked in our hospital and admitted to the maternity unit for delivery during the same period. Exclusion criteria were primigravidae, primipara, unbooked women, previous caesarean section, previous myomectomy, those who refused to participate in the study and those with pre-existing medical conditions such as diabetes mellitus and chronic hypertension. The study protocol was approved by the hospital research and ethics committee.

The study was performed over 7 months' period after the participants consented and met the inclusion criteria. During the period, all women who had previously given birth to five or more times (grandmultiparae) who met the inclusion criteria were recruited. The control group was selected to match each case for age. Each case was matched with a control woman, selected by identifying the first woman matched for age, delivering within the same period as the index case and had previously delivered two to four times (multiparae). The pattern was repeated until the desired sample was obtained. This was to reduce the reported effect of maternal age on the obstetric complications [12].

On admission, patients' histories were taken in details and the case file reviewed. A pretested questionnaire was used for the collection of biodata, obstetric history, socio-demographic data and antenatal complications of pregnancy by the researcher and also by trained residents attached to the labor ward. The data were obtained and filled by direct questioning, examination and follow up of the patients from admission till discharge from hospital. The maternal weight, blood pressure and fetal presentation were obtained and recorded. The fetal presentation was determined by abdominal palpation and when difficult, ultrasound was used to determine the fetal presentation. About $3 \mathrm{ml}$ of venous blood was collected from each woman with application of tourniquet into Ethylene Diamine Tetra Acetic acid (EDTA) anticoagulated container for packed cell volume. Midstream urine was collected in a sterile container for urinalysis using 
the dipstick method in the hospital labor ward side laboratory. During labor, patients were managed according to unit's protocol and partograph recording were used to evaluate the progress of labor. The intrapartum complications including prolonged labor, intrapartum hemorrhage, uterine rupture and mode of delivery were also recorded. After delivery, information on birth weight, Apgar scores and admission to neonatal intensive care unit (NICU) were obtained. Patients were monitored for 24 hours for primary postpartum hemorrhage. Also, data on maternal mortality, stillbirth and fetal malformation were obtained.

Anemia was defined as PCV of less than $30 \%$ as this is a more useful definition in the tropics [12]. Pre-eclampsia was defined as blood pressure of $>140 / 90$ $\mathrm{mm} \mathrm{Hg}$ after 20 weeks of gestation with proteinuria on two or more occasions of 6 hours apart. Bleeding from genital tract after 28 weeks gestation and before delivery was taken as APH. Malpresentation was defined as presentation of the fetus other than vertex presentation in relation to maternal pelvis. Preterm delivery was defined as delivery before 37 completed weeks of gestation. Primary $\mathrm{PPH}$ was defined as blood loss estimation of $500 \mathrm{ml}$ and above after normal vaginal delivery and $1000 \mathrm{ml}$ after caesarean section or such that could compromise the cardiovascular system within 24 hours of delivery.

\section{Results}

The mean age of the grand-multiparous women was $37.0 \pm 2.8$ years, and that of matched multiparous control group was $36.1 \pm 3.0$ years. Mean parity for the cases was $5.6 \pm 0.9$ while $3.0 \pm 0.8$ was for the control group.

Table 1 shows the socio-demographic characteristics of the study population. The grand multiparous women were significantly associated with educational levels $\left(\mathrm{X}^{2}=18.21, \mathrm{P}\right.$-value $\left.=0.000\right)$ and polygamous marriage $\left(\mathrm{X}^{2}=4.551\right.$, $\mathrm{P}$-value $=0.033)$. Grand-multiparous pregnancy was significantly more among the muslims in case group (17.3\%) than in the control group $(6.7 \%)\left[\mathrm{X}^{2}=8.081\right.$, P-value $=0.004]$.

The mean gestational age at delivery of the grand multiparous women was lower $(38.40 \pm 1.475$ weeks) than the control (38.64 \pm 1.338 weeks) though, the difference was not statistically significant $(\mathrm{t}$-test $=1.476$, P-value $=0.141)$ as shown in Table 2 . The mean packed cell volume at delivery for the grand multiparous women was lower $(33.59 \% \pm 2.727 \%)$ than the control $(35.21 \% \pm 2.728 \%)$ and this was statistically significant $(\mathrm{t}$-test $=5.143, \mathrm{P}$-value $=0.000)$.

Table 3 shows the antenatal complications of grand multiparous women and their controls. Pregnancy induced hypertension was significantly higher among grand multiparous women $8(5.3 \%)$ than the control $1(0.7 \%)(\mathrm{P}=0.018)$.

The packed cell volume of the participants decreases as the parity increases and showed a negative correlation with the parity as shown in Figure 1. The negative linear relationship between packed cell volume at delivery and parity was significant (Pearson correlation $=-0.301$; P-value $=0.000$ ).

Table 4 shows the intrapartum complications. Fetal distress and caesarean section were higher among grand multiparous women than their controls, 
Table 1. The socio-demographic characteristics of the study population.

\begin{tabular}{|c|c|c|c|c|c|}
\hline \multirow{2}{*}{ Variables } & \multirow{2}{*}{ Total } & \multicolumn{2}{|c|}{ Groups } & \multirow{2}{*}{$\mathrm{X}^{2}$} & \multirow{2}{*}{ P-value } \\
\hline & & Case (\%) & Control (\%) & & \\
\hline \multicolumn{6}{|l|}{ Age (Years) } \\
\hline$\leq 30$ & $4(1.3)$ & $1(0.7)$ & $3(2.0)$ & \multirow{4}{*}{2.989} & \multirow{4}{*}{0.393} \\
\hline $31-35$ & $105(35.0)$ & $48(32.0)$ & $57(38.0)$ & & \\
\hline $36-40$ & $157(52.3)$ & $81(54.0)$ & $76(50.7)$ & & \\
\hline$>40$ & $34(11.3)$ & $20(13.3)$ & $14(9.3)$ & & \\
\hline \multicolumn{6}{|l|}{ Level of Education } \\
\hline No Formal Education & $10(3.3)$ & $7(4.7)$ & $3(2.0)$ & \multirow{4}{*}{18.21} & \multirow{4}{*}{0.000} \\
\hline Primary & $139(46.3)$ & $72(48.0)$ & $67(44.7)$ & & \\
\hline Secondary & $111(37.0)$ & $63(42.0)$ & $48(32.0)$ & & \\
\hline Tertiary & $40(13.3)$ & $8(5.3)$ & $32(21.3)$ & & \\
\hline \multicolumn{6}{|l|}{ Religion } \\
\hline Christianity & $264(88.0)$ & $124(82.7)$ & $140(93.3)$ & \multirow{2}{*}{8.081} & \multirow{2}{*}{0.004} \\
\hline Islam & $36(12.0)$ & $26(17.3)$ & $10(6.7)$ & & \\
\hline \multicolumn{6}{|l|}{ Marriage Type } \\
\hline Monogamous & $281(93.7)$ & $136(90.7)$ & $145(96.7)$ & \multirow{2}{*}{4.551} & \multirow{2}{*}{0.033} \\
\hline Polygamous & $19(6.3)$ & $14(9.3)$ & $5(3.3)$ & & \\
\hline \multicolumn{6}{|l|}{ Birthweight } \\
\hline$<2.5$ & $9(3.0)$ & $6(4.0)$ & $3(2.0)$ & \multirow{3}{*}{2.937} & \multirow{3}{*}{0.230} \\
\hline $2.5-<4$ & $269(89.7)$ & $130(86.7)$ & $139(92.7)$ & & \\
\hline$\geq 4$ & $22(7.3)$ & $14(9.3)$ & $8(5.3)$ & & \\
\hline \multicolumn{6}{|l|}{ Weight At Delivery } \\
\hline $61-70$ & $36(12.0)$ & $20(13.3)$ & $16(10.7)$ & \multirow{6}{*}{13.26} & \multirow{6}{*}{0.021} \\
\hline $71-80$ & $46(15.3)$ & $20(13.3)$ & $26(17.3)$ & & \\
\hline $81-90$ & $97(32.3)$ & $39(26.0)$ & $58(38.7)$ & & \\
\hline $91-100$ & $79(26.3)$ & $47(31.3)$ & $32(21.3)$ & & \\
\hline $101-110$ & $30(10.0)$ & $14(9.3)$ & $16(10.7)$ & & \\
\hline$>111$ & $12(4.0)$ & $10(6.7)$ & $2(1.3)$ & & \\
\hline \multicolumn{6}{|l|}{ Tribe } \\
\hline Efik & $133(44.3)$ & $53(35.3)$ & $80(53.3)$ & \multirow{5}{*}{12.862} & \multirow{5}{*}{0.012} \\
\hline Hausa & $37(12.3)$ & $26(17.3)$ & $11(7.3)$ & & \\
\hline Ibibio & $53(17.7)$ & $30(20.0)$ & $23(15.3)$ & & \\
\hline Ibo & $59(19.7)$ & $31(20.7)$ & $28(18.7)$ & & \\
\hline Yoruba & $18(6.0)$ & $10(6.7)$ & $8(5.3)$ & & \\
\hline Occupation & & & & & \\
\hline Civil Servant & $71(23.7)$ & $28(18.7)$ & $43(28.7)$ & & \\
\hline Housewife & $65(21.7)$ & $30(20.0)$ & $35(23.3)$ & & \\
\hline Trader & $77(25.7)$ & $46(30.7)$ & $31(20.7)$ & 10.986 & 0.019 \\
\hline Artisans & $68(22.7)$ & $39(26.0)$ & $29(19.3)$ & & \\
\hline Students & $19(6.3)$ & $7(4.7)$ & $12(8.0)$ & & \\
\hline
\end{tabular}


Table 2. Shows the mean age, parity, gestational age and the birth weight at delivery in the study.

\begin{tabular}{ccccc}
\hline & \multicolumn{2}{c}{ Groups } & & \\
\cline { 2 - 3 } Characteristics & $\begin{array}{c}\text { Cases } \\
\text { Mean (S.D) }\end{array}$ & $\begin{array}{c}\text { Controls } \\
\text { Mean (S.D) }\end{array}$ & T-test & P-value \\
& $5.63( \pm 0.924)$ & $3.03( \pm 0.750)$ & 26.76 & 0.000 \\
Parity & $38.40( \pm 1.475)$ & $38.64( \pm 1.338)$ & 1.476 & 0.141 \\
Gestational Age (Weeks) & $85.92( \pm 11.776)$ & $89.31( \pm 8.689)$ & 2.837 & 0.005 \\
Maternal weight at delivery $(\mathrm{kg})$ & $3.393( \pm 0.585)$ & $3.339( \pm 0.4670)$ & 0.894 & 0.372 \\
Birth Weight (Kg) & $33.59( \pm 2.727)$ & $35.21( \pm 2.728)$ & 5.143 & 0.000 \\
\hline Packed cell volume $(\%)$ & & & & \\
\hline
\end{tabular}

Table 3. Shows ante-natal complications.

\begin{tabular}{ccccc}
\hline \multirow{2}{*}{ Complications } & \multirow{2}{*}{ Total } & \multicolumn{2}{c}{ Group } & \multirow{2}{*}{ P-value } \\
\cline { 3 - 4 } & & Case (\%) & Control (\%) & \\
\hline PROM & $26(8.7)$ & $15(10.0)$ & $11(7.3)$ & 0.412 \\
Preterm Labor & $10(3.3)$ & $7(4.7)$ & $3(2.0)$ & 0.198 \\
Malaria & $45(15.0)$ & $20(13.3)$ & $25(16.7)$ & 0.419 \\
Anemia & $22(7.3)$ & $15(10.0)$ & $7(4.7)$ & 0.764 \\
PIH & $9(3.0)$ & $8(5.3)$ & $1(0.7)$ & 0.018 \\
GDM & $1(0.3)$ & $1(0.7)$ & $0(0.0)$ & 0.317 \\
Placenta Previa & $3(1.0)$ & $2(1.3)$ & $1(0.7)$ & 0.562 \\
Abruptio Placentae & $1(0.3)$ & $1(0.7)$ & $0(0.0)$ & 0.317 \\
Malpresentation & $12(4.0)$ & $7(4.7)$ & $5(3.3)$ & 0.420 \\
Multiple Pregnancy & $6(2.0)$ & $5(3.3)$ & $1(0.7)$ & 0.099 \\
\hline
\end{tabular}

PIH: Pregnancy induced hypertention; GDM: gestational diabetes mellitus; PROM: Premature rupture of membranes.

Table 4. Shows the complications in labor.

\begin{tabular}{ccccc}
\hline \multirow{2}{*}{ Complications } & \multirow{2}{*}{ Total } & \multicolumn{2}{c}{ Group } & \multirow{2}{*}{ P-value } \\
\cline { 3 - 4 } & & Case (\%) & Control (\%) & \\
\hline Prolonged Labor & $1(0.3)$ & $1(0.7)$ & $0(0.0)$ & 0.317 \\
Fetal Distress & $19(6.3)$ & $12(8.0)$ & $7(4.7)$ & 0.236 \\
Cephalopelvic Disproportion & $19(6.3)$ & $11(7.3)$ & $8(5.3)$ & 0.477 \\
Instrumental Delivery & $7(2.3)$ & $3(2.0)$ & $4(2.7)$ & 0.236 \\
Caesarean Section & $56(18.7)$ & $35(23.3)$ & $21(14.0)$ & 0.174 \\
\hline
\end{tabular}

however, they were not statistically significant $(\mathrm{P}$-value $=0.236)$ and $(\mathrm{P}$-value $=$ 0.174 ) respectively.

Primary postpartum hemorrhage was significantly higher in grand multiparous women $(7.3 \%)$ compared to $2.0 \%$ in control $(\mathrm{P}$-value $=0.029)$ as presented in Table 5. However, eclampsia, retained placenta and puerperal sepsis were not statistically significant among the study groups.

Table 6 shows the perinatal complications of both groups. Apgar less than 7 


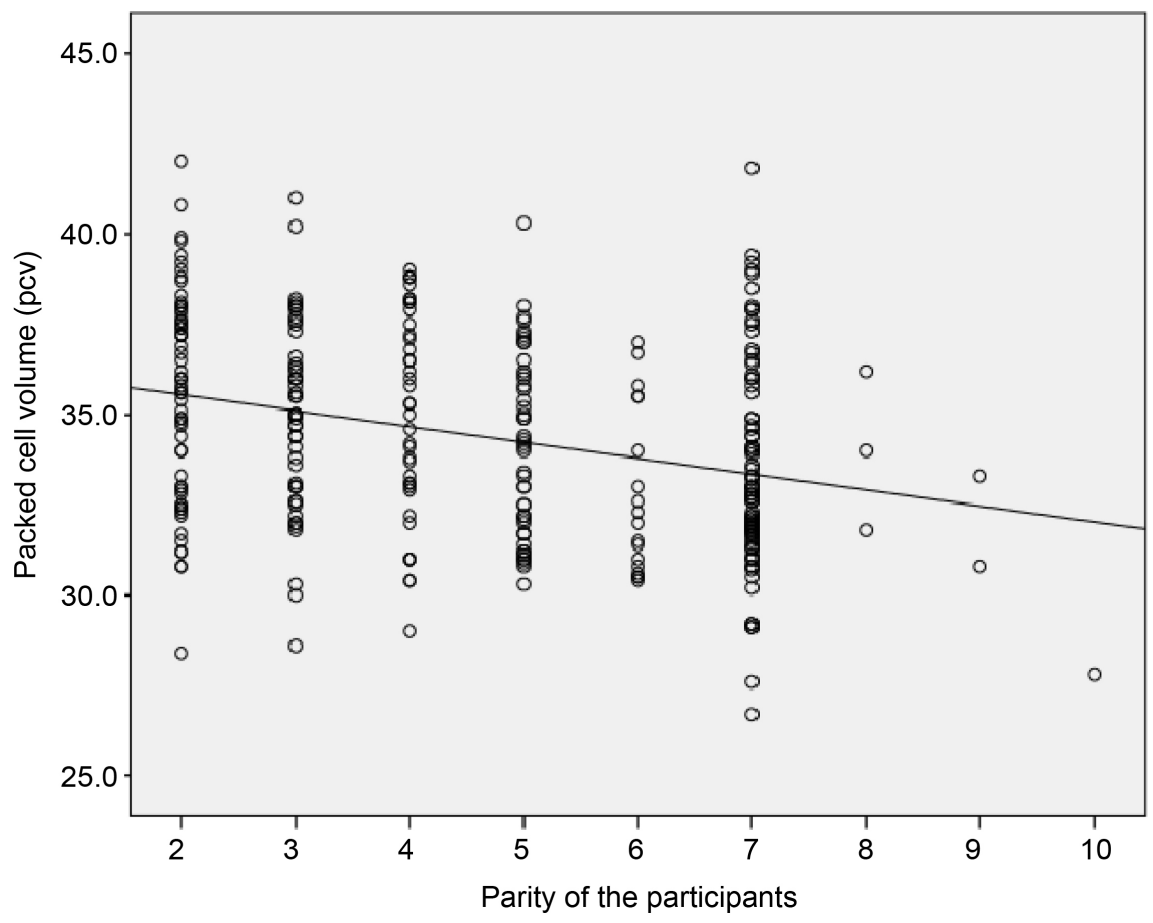

Figure 1. The scatter diagram of parity of the participants and their packed cell volume at delivery.

Table 5. The postpartum/puerperal complications.

\begin{tabular}{ccccc}
\hline \multirow{2}{*}{ Complications } & \multirow{2}{*}{ Total } & \multicolumn{2}{c}{ Group } & \multirow{2}{*}{ P-Value } \\
\cline { 3 - 4 } & & Case (\%) & Control (\%) & \\
\hline PPH & $14(4.7)$ & $11(7.3)$ & $3(2.0)$ & 0.029 \\
Eclampsia & $1(0.3)$ & $1(0.7)$ & $0(0.0)$ & 0.317 \\
Retained Placenta & $7(2.3)$ & $3(2.0)$ & $4(2.7)$ & 0.702 \\
Puerperial Sepsis & $1(0.3)$ & $1(0.7)$ & $0(0.0)$ & 0.317 \\
\hline
\end{tabular}

Table 6. The perinatal complications.

\begin{tabular}{ccccc}
\hline \multirow{2}{*}{ Complications } & \multirow{2}{*}{ Total } & \multicolumn{2}{c}{ Group } & \multirow{2}{*}{ P-value } \\
\cline { 3 - 4 } & & Case (\%) & Control (\%) & \\
\hline Apgar score ( $\leq 7$ at 1 min) & $71(23.7)$ & $40(26.7)$ & $31(20.7)$ & 0.221 \\
Apgar score ( 5 7 at 5 min) & $19(6.3)$ & $12(8.0)$ & $7(4.7)$ & 0.236 \\
Macrosomia & $22(7.3)$ & $14(9.3)$ & $8(5.3)$ & 0.184 \\
Lowbirth weight & $9(3.0)$ & $6(4.0)$ & $3(2.0)$ & 0.310 \\
Stillbirth & $3(1.0)$ & $2(1.3)$ & $1(0.7)$ & 0.562 \\
Admission to neonatal unit & $32(10.7)$ & $19(12.7)$ & $13(8.7)$ & 0.262 \\
Fetal malformation & $1(0.3)$ & $1(0.7)$ & $0(0.0)$ & 0.317 \\
Early neonatal death & $3(1.0)$ & $1(0.7)$ & $2(1.3)$ & 0.562 \\
\hline
\end{tabular}

in fifth minute was higher in grandmultiparous women (8.0\%) than the control (4.7\%) though, the difference was not statistically significant ( $\mathrm{P}$-value $=0.236$ ). Other perinatal complications in cases and controls were macrosomia $9.3 \%$ ver- 
sus $5.3 \%(\mathrm{p}$-value $=0.184)$ and early neonatal death $0.7 \%$ versus $1.3 \%(\mathrm{P}$-value $=$ $0.562)$.

\section{Discussion}

The peak age incidence of grand multiparity from this study was 36 - 40 years and it is similar to findings in Ilorin, but higher than earlier ones in Lagos (30 34 years) and Maiduguri (26 - 30 years) [13] [14] [15] [16]. This show that most grand multiparous women in this area continue more or less to get pregnant till age related sub-fertility sets-in, this current time when humanity should be civilised/advanced for this situation. Only about $13.3 \%$ of the grand multiparous were aged 41 and above, reflecting possible early ages at marriage and child bearing in our environment.

Grand multiparity was higher among women with primary level of education (48.0\% versus $44.7 \%)$, secondary education $(42.0 \%$ versus $32.0 \%)$ and no formal education $(4.7 \%$ versus $2.0 \%)$ than their control. This shows that the more the deliveries, the less money for education and training of the children and vicious circle continues. However, those with tertiary educational status were less likely to be grand multiparous than the control. This finding is similar to a study in Ilorin, Nigeria [13]. This shows that female education is the key in making informed choices about available reproductive health care services and reduction of grand multiparity. Grand multiparity is significantly more associated with polygamous marriage and Islamic religion. This is not unexpected as the culture of polygamous marriage and large family size is common among Muslims. Also, previous study had shown that awareness and uptake of contraceptives were higher among Christians [1].

Analysis of antenatal complications revealed that premature rupture of fetal membranes, preterm labor, placenta previa and anemia were more common among grand-multiparous women than the control; however, they were not statistically significant. Anemia has been a very frequently cited significant complication of grand-multiparous women due to poor child spacing, lower social status, non-compliance to haematinics intake and poor nutrition [9] [17]. However, anemia was not significantly higher in grand multiparous women in this study. The difference may be because; all the participants in this study were booked and received haematinics and anti-malaria during pregnancy with reduction in the rate of anemia. Grand-multiparity was significantly associated with pregnancy induced hypertension in this study. Though pregnancy induced hypertension is generally considered to be a disease of the primigravidae, advanced maternal age associated with grand multiparity has been linked with its increased incidence [18]. Also, there was a higher incidence of malaria in the control group (16.7\%) compared to the grand-multiparous women (13.3\%) although, the difference was not significant. This is a reflection of the lower level of malaria immunity or antibodies that block binding of malaria infected red blood cells to chondroitin sulphate A in the syncytiotrophoblast in the lower parity women [19]. 
The mean packed cell volume at delivery for the grand multiparous women was lower $(33.6 \% \pm 2.7 \%)$ than the control $(35.2 \% \pm 2.7 \%)$ and this was statistically significant. Also, the packed cell volume of the participants decreases as the parity increases and showed a negative correlation with the parity. This may be as a result of short birth interval, low socioeconomic status with consequent depletion of iron stores [12]. This is similar to the finding in a study in United Kingdom which showed that grand multiparous women significantly had less haemoglobin concentration during antenatal period than multiparous women [17].

Findings noted in the intrapartum period were higher incidences of prolonged labor, fetal distress and also cephalopelvic disproportion among grand multiparous women than controls, although, they were not statistically significant. Primary postpartum hemorrhage was significantly higher among grand multiparous women $(7.3 \%)$ than the control $(2 \%)$ in this study. This is comparable to $6.2 \%$ in Ilorin, but higher than $2.4 \%$ in Maiduguri [13] [14]. The commonest predisposing factor was uterine atony resulting from increased deposition of fibrous tissue in the myometrium following repeated deliveries. There is decline in uterine contractility after many pregnancies, impaired full myometrial retraction because of scarring, exhaustion and atherosclerotic changes in uterine vasculature with less efficient clamping off of uterine vasculature postpartum in grand multiparous women [12] [13]. However, the other postpartum complications such as eclampsia, puerperal sepsis and retained placenta were not significant higher among grand-multiparous women. Fortunately, there was no maternal death in both groups which is also a reflection of the antenatal and intrapartum care they received as opposed to relatively high maternal death among the unbooked grand-multiparous women who delivered outside the hospital settings or present to the hospital with complications of pregnancy [13] [20]. This is related to the role of good antenatal care, careful management of labor with judicious use of oxytocics and availability of blood transfusion services.

There was no significant difference in perinatal outcome of grand multiparous women and the control in this study. Although, the fifth minute Apgar score less than 7 , stillbirth rate, low birth weight and admission to neonatal unit were higher among the grand multiparous women than the control, they were not statistically significant. Studies from developed countries are increasingly reporting fewer perinatal complications among the grand multiparous women [8] [17]. This study indicates that with booking for antenatal care and adequate perinatal care including labor supervision by skilled attendants, grand-multiparity is not associated with a significantly increased risk of the classic complications traditionally associated with it as compared to multiparous women. This finding agrees with a study which demonstrated that grand multiparity with modern medical care is not a major risk factor for adverse perinatal outcome [21]. Hence, in countries where socioeconomic status of women is high with standard antenatal and perinatal care, high parity is no longer considered a risk marker for perinatal complications as revealed in this study. 


\section{Conclusion and Recommendation}

The study revealed that grand multiparity is still common in our region. The grand-multiparity was significantly higher among women with lower educational levels, polygamous marriage and muslims. Pregnancy induced hypertension and primary postpartum hemorrhage were significantly higher among grand multiparous women than the control. This study therefore shows that grandmultiparous women are at increased risk of obstetric complications in our environment but with adequate antenatal surveillance, good intrapartum and postpartum care, with complication readiness attitude of care during labor and delivery, the problems will be highly minimized. Comprehensive maternal health care services can further be enshrined and implemented in our national health policies to ensure adequate care to all grand-multiparous women so as to reduce the possible morbidities and mortalities associated with this avoidable condition. Modern contraception counseling and utilization are very important factors in reducing perinatal mortality, infant mortality and maternal mortality and should be promoted. Recent developments have made female permanent contraception an increasingly attractive option more importantly among grand- multiparous women and all pregnant women should be counseled about it. Also, grand multiparity should not just be tackled purely as a health challenge but also as a socio-economic problem.

\section{Limitations of the Study}

The limitation of this study is lack of an account of some confounding factors which can affect the pregnancy outcome in the study such as inter-pregnancy interval, gestational age at delivery, nutritional status and psychosocial status of the woman. However, controlling for age in this study reduced the effects of confounding factors on the outcome. Also, obstetric outcome of grand multiparous women in a tertiary institution may differ from those of lower centers like primary and some secondary health centres; therefore, caution is required in translating these institutional study results based on outcome measures to the general population.

\section{Conflict of Interests}

The authors declare that there was no conflict of interests regarding the publication of this paper.

\section{Funding}

The author(s) received no financial support for the research, authorship, and/or publication of this article.

\section{References}

[1] Afolabi, A.F. and Adeyemi, A.S. (2013) Grand-Multiparity: Is It Still an Obstetric Risk? Open Journal of Obstetrics and Gynaecology, 3, 411-415. https://doi.org/10.4236/ojog.2013.34075 
[2] Shaista, T.A., Shazia, S., Fouzia, B.S. and Rafia, B. (2009) Obstetrical Complication in Grand Multi Parity. Medical Channel, 12, 53-58.

[3] Okogbenin, S.A. and Okpere, E.E. (2004) Parity and Reproductive Outcome. In: Okpere, E.E., Ed., Clinical Obstetrics Revised Edition, Uniben Press Ltd., University of Benin, Nigeria, 401-402.

[4] Centers for Disease Control and Prevention (2004) National Survey of Family Growth. Centers for Disease Control and Prevention, Atlanta.

[5] Eze, J.N., Okaro, J.M. and Okafor, M.H. (2006) Outcome of Pregnancy in the Grandmultipara in Enugu, Nigeria. Tropical Journal of Obstetrics and Gynaecology, 23, 8-11. https://doi.org/10.4314/tjog.v23i1.14555

[6] Ogbe, A.E., Ogbe, B.P. and Ekwempu, C. (2010) Obstetric Outcome in Grand-Multiparous Women in Jos University Teaching Hospital. Jos Journal of Medicine, 6, $1-5$.

[7] Begum, S. (2003) Age and Parity Related Problems Affecting Outcome of Labour in Grand Multipara. Journal of the Pakistan Medical Association, 42, 179-183.

[8] Mor-Yosef, S., Seidman, D.S., Samueloff, A. and Schenker, J.G. (1990) The Effects of the Socioeconomic Status on the Perinatal Outcome of Grandmultipara. European Journal of Obstetrics \& Gynecology and Reproductive Biology, 36, 117-123. https://doi.org/10.1016/0028-2243(90)90057-8

[9] Nordin, N.M., Fen, C.K., Isa, S. and Symonds, E.M. (2006) Is Grandmultiparity a Significant Risk Factor in This New Millennium? Malaysian Journal of Medical Sciences, 13, 52-60.

[10] Shah, P.S. (2010) Parity and Low Birth Weight and Preterm Birth: A Systematic Review and Meta-Analyses. Acta Obstetricia et Gynecologica Scandinavica, 89, 862875. https://doi.org/10.3109/00016349.2010.486827

[11] Joseph, G.O., Simon, O.E. and Felix, U.A. (2010) The Population Situation in Cross River State of Nigeria and Its Implication for Socio-Economic Development: Observation from the 1991 and 2006 Censuses. Journal of Emerging Trends in Educational Research and Policy Studies (JETERAPS), 1, 36-42.

[12] Chukwudebelu, W.O. (2003) Preventing Maternal Mortality in Developing Countries. In: Okonofua, F. and Odunsi, K., Eds., Contemporary Obstetrics and Gynaecology for Developing Countries. Women's Health and Action Research Centre (WHARC), Benin, 644-657.

[13] Omokanye, L.O. (2012) Obstetric Outcome of Grandmultiparous Women in Ilorin, Nigeria: A Five Year Review. Nigerian Journal of Health Sciences, 12, 16-19. http://www.nigeran-jhs.org/

[14] Idrisa, A. and Nwobodo, E.I. (1998) The Problems of Grandmultipara as Seen at the University of Maiduguri Teaching Hospital, Nigeria. Nigerian Journal of Medicine, 7, 165-167.

[15] Eze, J.N., Okaro, J.M. and Okafor, M.H. (2006) Outcome of Pregnancy in the Grandmultipara in Enugu, Nigeria. Tropical Journal of Obstetrics and Gynaecology, 23, 8-11. https://doi.org/10.4314/tjog.v23i1.14555

[16] Ogedengbe, O.K. and Ogunmokun, A.A. (2003) Grandmultiparity in Lagos, Nigeria. Nigerian Postgraduate Medical Journal, 23, 374-377.

[17] Bugg, G.J, Atwal, G.S. and Maresh, M. (2002) Grandmultiparae in a Modern Setting. British Journal of Obstetrics and Gynaecology, 109, 249.

http://onlinelibrary.wiley.com/doi/10.1111/j.14710528.2002.01058.x/full https://doi.org/10.1111/j.1471-0528.2002.01058.x

[18] Abasiattai, A.M., Utuk, N.M. and Udoma, E.J. (2013) Grandmultiparity: Outcome 
of Delivery in a Tertiary Hospital in Southern Nigeria. Nigerian Journal of Medicine, 20, 345-348.

[19] Sowunmi, A. (2003) Malaria in Pregnancy. In: Okonofua, F. and Odunsi, K., Eds., Contemporary Obstetrics and Gynaecology for Developing Countries, Women's Health and Action Research Centre (WHARC), Benin, 502-513.

[20] Agbor, I.M. (2015) Sociological Implication of Sex Preference for Fertility and Marital Stability in Cross River State (doctoral dissertation, Ahmadu Bello University, Zaria). http://kubanni.abu.edu.ng:8080/jspui/bitstream/123456789/4036/1/

[21] D’ Souza, K., Francis, N.P.M., Jayaprakash, K., Prashantha, B. and Sheena, K. (2011) Spectrum of Grand-Multiparity. Journal of Clinical and Diagnostic Research, 5, 1247-1250.

Submit or recommend next manuscript to SCIRP and we will provide best service for you:

Accepting pre-submission inquiries through Email, Facebook, LinkedIn, Twitter, etc. A wide selection of journals (inclusive of 9 subjects, more than 200 journals)

Providing 24-hour high-quality service

User-friendly online submission system

Fair and swift peer-review system

Efficient typesetting and proofreading procedure

Display of the result of downloads and visits, as well as the number of cited articles

Maximum dissemination of your research work

Submit your manuscript at: http://papersubmission.scirp.org/

Or contact ojog@scirp.org 